\title{
Genetic polymorphism of merozoite surface protein 2 and prevalence of K76T pfcrt mutation in Plasmodium falciparum field isolates from Congolese children with asymptomatic infections
}

Felix Koukouikila-Koussounda, 1,2,, Vladimir Malonga', Pembe Issamou Mayengue ${ }^{1,2}$, Mathieu Ndounga 3,4, Christevy Jeannhey Vouvoungui ${ }^{1,2}$ and Francine Ntoumi ${ }^{1,2,5^{*}}$

\begin{abstract}
Background: In order to prepare the field site for future interventions, the prevalence of asymptomatic Plasmodium falciparum infection was evaluated in a cohort of children living in Brazzaville. Plasmodium falciparum merozoite surface protein 2 gene ( $m s p 2$ ) was used to characterize the genetic diversity and the multiplicity of infection. The prevalence of mutant $P$. falciparum chloroquine resistance transporter ( $p f c r t$ ) allele in isolates was also determined.

Methods: Between April and June 2010, 313 children below 10 years of age enrolled in the cohort for malaria surveillance were screened for $P$. falciparum infection using microscopy and polymerase chain reaction (PCR). The children were selected on the basis of being asymptomatic. Plasmodium falciparum msp2 gene was genotyped by allele-specific nested PCR and the pfcrt K76T mutation was detected using nested PCR followed by restriction endonuclease digestion.

Results: The prevalence of asymptomatic $P$. falciparum infections was $8.6 \%$ and $16 \%$ by microscopy and by PCR respectively. Allele typing of the msp2 gene detected 55\% and 45\% of 3D7 and FC27 allelic families respectively. The overall multiplicity of infections (MOI) was 1.3. A positive correlation between parasite density and multiplicity of infection was found. The prevalence of the mutant pfcrt allele (T76) in the isolates was $92 \%$.

Conclusion: This is the first molecular characterization of $P$. falciparum field isolates in Congolese children, four years after changing the malaria treatment policy from chloroquine (CQ) to artemisinin-based combination therapy (ACT). The low prevalence of asymptomatic infections and $\mathrm{MOI}$ is discussed in the light of similar studies conducted in Central Africa.
\end{abstract}

Keywords: Plasmodium falciparum, Asymptomatic infection, Multiplicity of infection, msp2, pfcrt, Brazzaville, Republic of Congo

\section{Background}

Despite significant reduction in malaria-related morbidity and mortality in the recent past, malaria remains endemic in the tropics and sub-tropics including subSaharan Africa. About 225 million clinical cases and 781,000 deaths were reported worldwide in 2009, whereby almost $90 \%$ occurred in sub-Saharan Africa [1].

\footnotetext{
* Correspondence: fntoumi@fcrm-congo.com

'Congolese Foundation for Medical Research, Brazzaville, Republic of Congo Full list of author information is available at the end of the article
}

Current malaria control strategies include the use of insecticide-treated bed nets (ITNs), indoor residual spraying of insecticide, intermittent preventive treatment to young children and pregnant women, and early parasitological diagnosis and treatment of clinical cases using artemisinin-based combination therapy (ACT) [2-4]. Deployment of these strategies has had significant impact on malaria in many endemic areas.

Although the impact of current malaria control strategies is encouraging, much more remains to be done to 
attain elimination. In the meantime, malaria vaccine is considered as an additional necessary arsenal. However, genetic diversity in Plasmodium falciparum is a major limitation for the successful development of an effective malaria vaccine, as it influences the level and efficacy of acquired protective immunity to malaria. Therefore, screening of the genetic diversity of malaria parasite populations in different endemic settings is an important step towards the development and/or the evaluation of malaria vaccines [5].

Genotyping of merozoite surface protein-2 ( $m s p 2)$ is the commonly used method to study the genetic diversity of $P$. falciparum. This gene presents polymorphisms in the number of repeats and sequence type [6]. The analysis of msp 2 alleles involves two major allelic families, FC27 and 3D7. The $m s p 2$ gene is also the basis of determining the multiplicity of infections (MOI) in infected individuals, which is defined as the number of distinguishable $P$. falciparum clones per infected individual. MOI is a good indicator of acquired immunity or premunition of the populations living in endemic areas and is also correlated to the transmission intensity $[7,8]$. It has been demonstrated that MOI could be influenced by parasite density and age [9], and haemoglobin ( $\mathrm{Hb}$ ) type carriage [10].

Makélékélé is an administrative division in the southeastern part of Brazzaville (Republic of Congo), and has been well characterized as a highly endemic area with perennial malaria transmission $[11,12]$. However, there is a paucity of information on the genetic diversity of $P$. falciparum populations. Following the replacement of chloroquine (CQ) with ACT (artesunate-amodiaquine and artemether-lumefantrine as first and second line treatment respectively) in 2006 for the treatment of uncomplicated malaria in the Republic of Congo [13], CQ drug pressure has since been reduced. In Malawi, absence of CQ pressure was followed by the re-emergence of CQ-susceptible malaria, based on genotyping of CQ resistance biomarker, $P$. falciparum chloroquine resistance transporter gene (pfcrt) [14-16]. In Congo Brazzaville, molecular analysis of the parasite population, including the CQ resistance $p f c t \mathrm{~K} 76 \mathrm{~T}$ mutation has not been investigated since the change of anti-malarial treatment policy in 2006. Therefore, the present study was conducted in the semi-urban area of Makélékélé to determine (i) the prevalence and the multiplicity of P. falciparum asymptomatic infection; (ii) the genetic diversity of the msp 2 gene; and (iii) the prevalence of $p f c r t$ K76T mutation in P. falciparum isolates.

\section{Methods}

\section{Study site}

The study conducted under the auspices of the Central Africa Network on Tuberculosis, HIV/AIDS and Malaria (CANTAM) project, was carried out in three districts of
Makélékélé health division: Ngoko, Kinsana and Mbouono. These semi-urban divisions with about 6,000 inhabitants are located in the southern part of Brazzaville along the Congo River where malaria is transmitted throughout the year [12]. Plasmodium falciparum is the main plasmodial species and Anopheles gambiae the main mosquito vector.

\section{Study population}

Children aged one to nine years and permanent residents of the study area were enrolled in a cohort for malaria surveillance study (Ndounga et al, unpublished). From October 2009 to June 2010, a demographic survey was conducted and 313 children under 10 years were enrolled. Malaria incidence is 0.9 malaria episode/year/ child. Inclusion criteria were absence of clinical malaria in the last two weeks and at least one week after enrolment, and with an axillary temperature of $<37.5^{\circ} \mathrm{C}$. Recruitment was done from April to June 2010, and informed consent was obtained from parents or guardians. Thick and thin blood smears were made from each child. About $4 \mathrm{ml}$ of whole blood were also collected in EDTA tube for haemoglobin concentration measurement and DNA extraction. This study was approved by the Institutional Ethics Committee for Research on Heath Sciences of the Republic of Congo.

\section{Microscopic examination}

Thick and thin blood films were stained with $10 \%$ Giemsa for $15 \mathrm{~min}$ and read by two independent competent microscopists to determine malaria species and the parasite density. Asexual parasites were counted against 200 leucocytes and expressed as the number of asexual parasites/ $\mu$ l of blood, assuming the leucocyte count of $8,000 / \mu \mathrm{l}$ of blood.

\section{Genomic DNA extraction}

Genomic DNA was extracted from $200 \mu$ l of whole blood sample using the QIAmp DNA Blood Mini kit (QIAGEN Gmbh, Hilden, Germany) following the manufacturer's instruction. DNA was recovered in $200 \mu \mathrm{l}$ of elution buffer provided in the kit and stored at $-20^{\circ} \mathrm{C}$ until use.

\section{msp2 genotyping of plasmodium falciparum isolates}

To characterize parasite infection, $P$. falciparum genotyping was performed using a nested PCR for $m s p 2$ central region, which comprises repeats of varying lengths. The FC27 and 3D7 allele families were analysed. The specific oligonucleotide primers and PCR conditions were as previously described by Ntoumi et al [17].

\section{Pfcrt K76T PCR-typing}

The nested PCR followed by restriction enzyme digestion PCR reactions were used to genotype the Lysine to 
Threonine mutation in codon 76 of pfcrt as described by Mayengue et al [18], Djimde et al [19] and Mayor et al [20]. All isolates successfully amplified using $m s p 2$ PCR were assayed with the pfcrt PCR.

\section{Sickle cell trait}

$\beta$-globin genotypes $\mathrm{HbAA}, \mathrm{HbAS}$ and $\mathrm{HbSS}$ were determined using allele specific PCR method as described by $\mathrm{Wu}$ et al [21].

\section{Data analysis}

The prevalence of FC27 and 3D7 alleles was determined as the presence of PCR products for each type in the total number of amplified bands for the corresponding locus. The MOI was determined as the number of different $m s p 2$ genotypes per isolate, and the mean MOI was calculated as the total number of detected Plasmodium falciparum msp 2 genotypes/total number of infected children [18]. The msp 2 allelic frequency represents the ratio of one specific allele out of the total number of alleles identified in the isolates. The polyclonality (percentage of isolates with more than one amplified PCR fragment) was estimated for each group. Similarly, proportions of wild and mutant $p f c r t$ alleles were calculated as the ratio of each allele type out of the total of $P$. falciparum positive samples. Statistical analysis was done using XLSTAT software (Version 2011.2.08). The chisquare test was used to compare quantitative variables such as parasite prevalence and MOI between different groups. The Spearman's rank correlation coefficient was calculated to assess association between MOI and parasite density. Differences were considered statistically significant at $P$ values $<0.05$.

\section{Results}

\section{Baseline demographic data and parasitological indexes}

A total of 313 children aged from one to nine years (mean age: $4.4 \pm 2.5$ years) were enrolled in the study. Sickle cell trait was present in $58(18.5 \%)$ of them. The haemoglobin levels were distributed into 3 categories: normal $\geq 12.0 \mathrm{~g} /$ $\mathrm{dl}(23.3 \%$ of children), moderate anemia $11.9 \mathrm{~g} / \mathrm{dl}-7.0 \mathrm{~g} / \mathrm{dl}$ $(72.2 \%)$ and severe anemia $<7 \mathrm{~g} / \mathrm{dl}(1.3 \%)$.

The prevalence of asymptomatic parasitaemia detected microscopically was $8.6 \%, P$. falciparum being the only infecting specie. The parasite density ranged from 62 to 16,090 parasites/ $\mu$ land a geometric mean density of 3,421 parasites $/ \mu$ l. Through PCR amplification of $m s p 2$ gene, $P$. falciparum infection was detected in $16 \%$ of the isolates (Table 1).

The prevalence of infection (by microscopy and PCR) varied according to the age of children $(\mathrm{P}<0.05)$, being highest in the seven to nine years age group (14 and $26 \%$ respectively), followed by four to six years (11 and $17 \%)$, and one to three years age group (3.5 and 7\%).
Table 1 Demographic data and parasitological indexes of the study population

\begin{tabular}{|c|c|}
\hline Parameters & Values \\
\hline Mean age (year) & $4.4 \pm 2.5$ \\
\hline Age range & $1-9$ \\
\hline Sex ratio $(M / F)$ & $1.1(168 / 146)$ \\
\hline Mean axillary temperature $\left({ }^{\circ} \mathrm{C}\right)$ & $36.5 \pm 0.3$ \\
\hline Axillary temperature range $\left({ }^{\circ} \mathrm{C}\right)$ & $36-37.4$ \\
\hline Mean hematocrit (g/dl) & 10.0 \\
\hline $\mathrm{Hb} \geq 12.0 \mathrm{~g} / \mathrm{dl} \mathrm{n}(\%)$ & $73(23.3 \%)$ \\
\hline $\mathrm{Hb} 7.0 \mathrm{~g} / \mathrm{dl}-11.9 \mathrm{~g} / \mathrm{dl} \mathrm{n}(\%)$ & $226(72.2 \%)$ \\
\hline $\mathrm{Hb}<7.0 \mathrm{~g} / \mathrm{dl} \mathrm{n}(\%)$ & $4(1.3 \%)$ \\
\hline $\mathrm{Hb}$ not determined & $10(3.2 \%)$ \\
\hline $\mathrm{HbAA}, \mathrm{n}(\%)$ & $255(81.5 \%)$ \\
\hline $\mathrm{HbAS}, \mathrm{n}(\%)$ & $58(18.5 \%)$ \\
\hline HbSS, n(\%) & 0 \\
\hline \multicolumn{2}{|l|}{ P. falciparum prevalence, $\mathrm{n}(\%)$} \\
\hline Microscopy & $27(8.6 \%)$ \\
\hline PCR & $51(16.0 \%)$ \\
\hline Geometric mean parasite density $(\mathrm{p} / \mu \mathrm{l})$ & 3,421 \\
\hline Parasite density range $(\mathrm{p} / \mu \mathrm{l})$ & $62-16,090$ \\
\hline Mean MOI & 1.3 \\
\hline MOl-range & $1-3$ \\
\hline \multicolumn{2}{|l|}{ pfcrt K76T prevalence $\mathrm{n}(\%)^{*}$} \\
\hline Wild type & $4(8 \%)$ \\
\hline Mutant type & $47(92 \%)$ \\
\hline Number of individuals & 313 \\
\hline
\end{tabular}

* Prevalence determined among PCR positive samples

\section{Merozoite surface protein 2 genetic diversity}

Alleles were determined by size and family type. Allele typing showed the highly polymorphic nature of $P$. falciparum isolates. Both 3D7 and FC27 families were identified with 8 and 10 different alleles respectively (Figure 1). The proportion of isolates having only 3D7 and FC27 alleles was 23/51 (45\%) and 18/51 (35\%) respectively. Both allelic families were found in $7 / 51$ (14\%) of the isolates. Six per cent (6\%) of the isolates were not identified to any of the 3D7 or FC27 allelic family despite being repeatedly amplified (Table 2 ). This might be due to a mutation in the annealing region of the primers.

\section{Multiplicity of plasmodium falciparum infection}

In this study, $74 \%$ of the infections analysed consisted of a single $m s p 2$ genotype, $22 \%$ were double infection and $4 \%$ triple. The overall MOI was 1.3 and similar in all age groups. The proportion of samples with more than one clone was higher in both one to three and four to six years age groups ( 33.3 and $27.8 \%$ respectively) compared to the seven to nine years olds group (19\%) (Table 3). However, the difference was not statistically significant. 


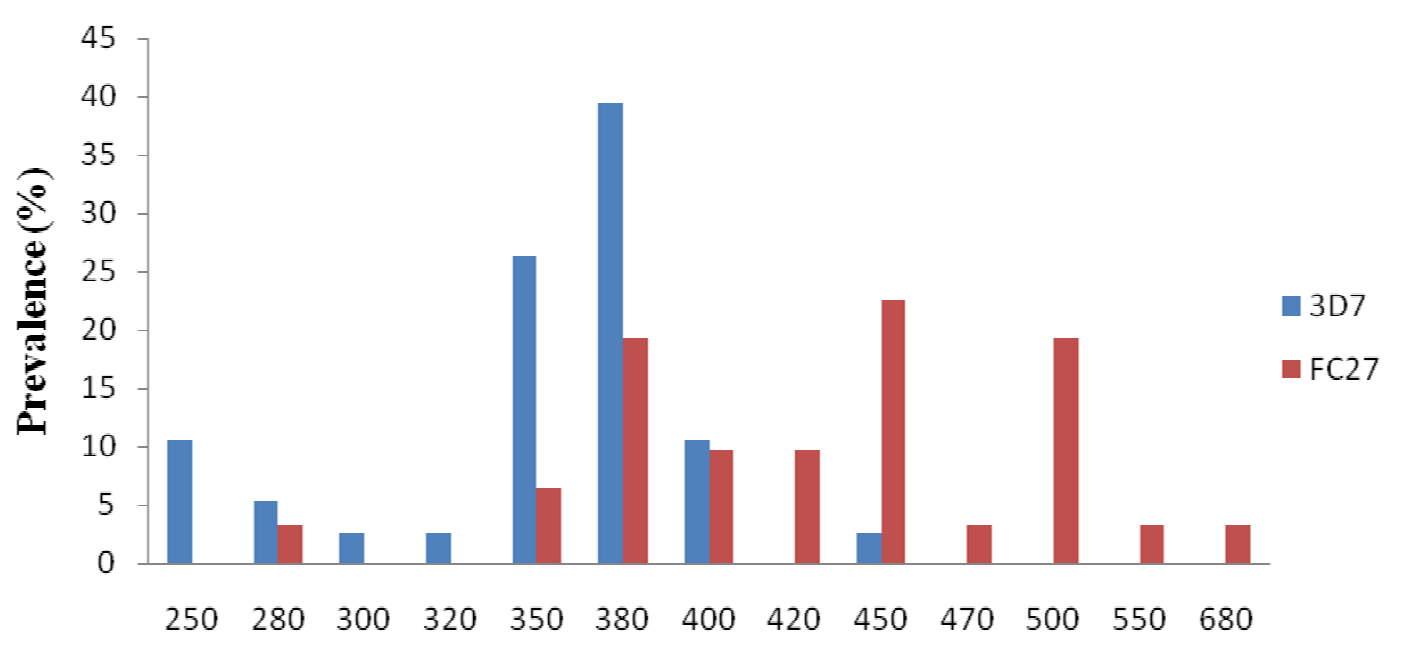

Alleles (Size by base pairs)

Figure 1 Distribution of $P$. falciparum 3D7 and FC27 msp2 alleles

The haemoglobin phenotype (AA or AS) had no influence on MOI. The prevalence of multiple infections in AA group was 19\% compared with $27 \%$ in AS group, and this difference was not significant (Table 3). Nonetheless, a significant positive association was found between P. falciparum parasite density and MOI (Spearman rank coefficient $=0.4489, P=0.0278)($ Figure 2$)$.

\section{Prevalence of pfcrt K76T mutation}

Genotyping of the pfcrt gene showed that 47 isolates out of 51 (92\%) produced the expected 134 bp amplicon, suggesting the presence of T76 mutation. Four isolates (8\%) with the wild type were found (Table 1).

\section{Discussion}

In the Republic of Congo, less attention had been put on the investigation of the genetic diversity of $P$. falciparum among asymptomatic parasite carriers. Besides, this analysis is necessary to develop strategies for malaria control including the design of malaria vaccines interventions. The current study is the first of its kind to evaluate genetic diversity of $P$. falciparum isolates circulating among children younger than 10 years old, and to present the molecular analysis of pfcrt gene since the replacement of chloroquine with $\mathrm{ACT}$ as the first line antimalarial drug in Congo Brazzaville.

The prevalence of $P$. falciparum carriage of $8.6 \%$ (microscopically) and 16\% (by PCR) is low compared to those reported previously from other malaria endemic areas $[9,10,22]$. However, these findings are in line with the results of a recent study conducted in Gabon that showed a relatively low prevalence of asymptomatic $P$. falciparum infection of $5 \%$ by microscopy among young children [23]. In the recent past, a large number of ITNs were available to children under five years of age and to pregnant women in the Republic of Congo. The observed low prevalence could be attributed to the wide use of the ITNs. Further investigations involving more children and adults would be of great importance to confirm this finding.

Allele-specific genotyping of $m s p 2$ has shown that P. falcuparum population in this part of the Republic of Congo have a high genetic diversity. Dispite the fact that a high proportion of isolates $(74 \%)$ carried one

Table 2 Genetic diversity of $\boldsymbol{P}$. falciparum msp 2 gene

\begin{tabular}{llllll}
\hline & No. of samples & Prevalence (\%) & Fragment size (bp) & Total No. of alleles $^{\text {a }}$ & Allelic frequency $^{\text {b }}$ \\
\hline 3D7 & 23 & 45 & $250-450$ & 38 & 55 \\
FC27 & 18 & 35 & $280-680$ & 31 & 45 \\
FC27 + 3D7 & 7 & 14 & & & \\
Non identified & 3 & 6 & & 69 & 100 \\
Total & 51 & 100 & & & \\
\hline
\end{tabular}

No. Number

a Total number of alleles is the number of different msp2 alleles distinguished by the size and the family type (3D7 and FC27)

${ }^{b}$ Allelic frequency is defined as the ratio of 3D7 or FC27 alleles out of the total number of msp2 alleles 
Table 3 Comparison of the parasite prevalence, parasite density and the MOI in different age groups and haemoglobin $(\mathrm{Hb})$ phenotypes

\begin{tabular}{|c|c|c|c|c|c|c|c|}
\hline & \multicolumn{3}{|l|}{ Age groups } & \multirow[t]{3}{*}{$P$} & \multicolumn{2}{|l|}{ Hb type } & \multirow[t]{3}{*}{$P$} \\
\hline & $1-3$ & 4-6 & $7-9$ & & $\overline{A A}$ & AS & \\
\hline & $N=137$ & $\mathrm{~N}=96$ & $\mathrm{~N}=80$ & & $\mathrm{~N}=255$ & $\mathrm{~N}=58$ & \\
\hline \multicolumn{8}{|l|}{ Parasite prevalence $\mathrm{n}(\%)$} \\
\hline Microscopy & $5(3.5 \%)$ & $11(11 \%)$ & $11(14 \%)$ & 0.018 & $19(7.5 \%)$ & $8(13.5 \%)$ & NS \\
\hline PCR & $12(8.8 \%)$ & $18(17 \%)$ & $21(26 \%)$ & 0.002 & $40(15.5 \%)$ & $11(19 \%)$ & NS \\
\hline Geometric mean parasite density $(p / \mu l)$ & 1,246 & 3,442 & 3,024 & NS & 4,052 & 2,081 & NS \\
\hline Mean MOI & 1.3 & 1.3 & 1.2 & NS & 1.3 & 1.4 & NS \\
\hline Proportion of multiple infections* & 4/12(33.3\%) & $5 / 18(27.8 \%)$ & 4/21(19\%) & NS & $8 / 40(19 \%)$ & $3 / 11(27 \%)$ & NS \\
\hline
\end{tabular}

* Proportion of multiple infections in PCR positive samples, NS non significant

genotype in comparison to those having two and three genotypes, different types of both 3D7 and FC27 alleles were found. The proportion of 3D7 alleles (55\%) was slightly high compared with that of FC27 (45\%). This is similar to findings in Papua New Guinea [22].

The MOI (number of concurrent msp 2 genotypes in individual infections) ranged from 1 to 3 . The mean MOI of 1.3 is relatively low compared to those reported in Gabon [24], Senegal [9,25], and Ghana [26] in asymptomatic cases. This might be explained by the fact that diversity of $P$. falciparum population differs according to the geographic location, and the level of transmission $[27,28]$. In the same study area [29], the MOI in isolates from symptomatic children was 2.2 . The interpretation of this increase in the mean number of parasite genotype/infected child could be the presence of the uncontrolled strain causing the symptoms.

Age is one of the suggested important factors involved in the acquisition of immunity against $P$. falciparum and influences MOI [9]. On the contrary, these results show that age has no effect on MOI. The absence of influence of age on MOI has also been previously reported in the same area among $P$. falciparum symptomatic children by Pembe et al [29].

Previous studies on association between MOI and parasite densities showed that high parasite densities increase the probability of detecting concurent clones in an individual $[30,31]$. Expectedly, a positive correlation between MOI and parasite density was found in the present study.

The impact of sickle cell trait on MOI in this study is different from findings in Gabon by Ntoumi et al [10], in which, a correlation between sickle cell trait and MOI was found. However, this observation corroborates reports from Senegale by Konate et al [32] and Vafa et al [9] whereby no correlation was found. These discrepancies can be explained by differences in age ranges of the study population and the number of individuals with sickle cell trait enrolled.

The prevalence of $p f c r t \mathrm{~K} 76 \mathrm{~T}$ was also assessed, the mutation associated with $\mathrm{CQ}$ resistance. It was anticipated that the sensitivity of the parasite to CQ may have been restored several years after its withdrawal as was the case

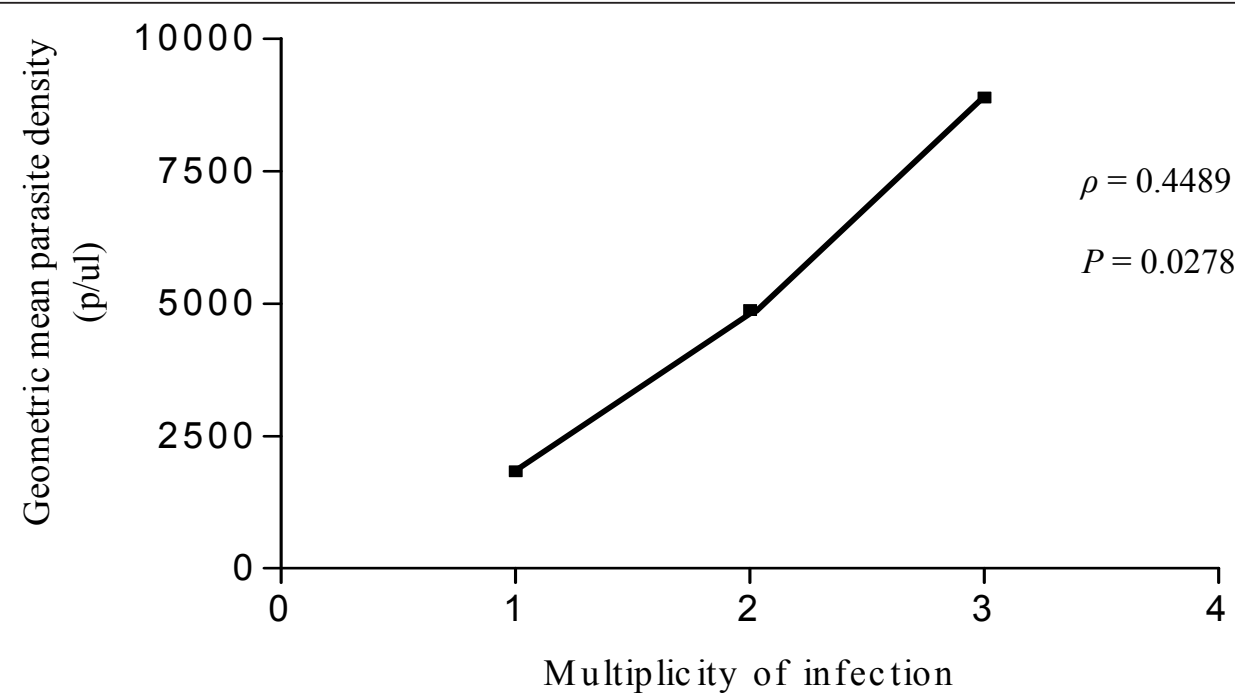

Figure 2 Correlation of $m s p 2$ multiplicity of infection and mean Plasmodium falciparum parasite density Spearman rank coefficient $=$ $0.4489, P=0.0278$. 
in Malawi [16]. The prevalence of Pfcrt K76T, an important molecular marker surveillance tool that can contribute to the evaluation of local parasite strains sensitivity to CQ in addition to in vitro studies [33], was $98 \%$ in Congo before withdrawal of CQ [18]. Almost five years later, this study shows that the prevalence of this mutation remains high, $92 \%$. This observation is similar to a recent report by Efunshile et al in Nigeria [34]. Therefore, CQ cannot be re-introduced in Congo now despite its many advantages over other anti-malarials.

\section{Conclusion}

In summary, these findings shows that multiplicity of infection which is low in Congolese children with asymptomatic $P$. falciparum infection increases with parasite density. The prevalence of the mutant $p f c r t$ allele remains extremely high in the study area. Further investigations with larger sample size in different zones of the country would be needed to confirm these observations.

\section{Abbreviations \\ msp2: merozoite surface protein 2 gene; pfcrt: Plasmodium falciparum chloroquine resistance transporter; PCR: Polymerase chaine reaction; $\mathrm{MOI}$ : Multiplicity of infection; ITN: Insecticide-treated bed net; ACT: Artemisinin- based combination therapy; CQ: Chloroquine; Hb: Heamoglobin; UV: Ultraviolet; bp: Base pair; dNTP: Deoxynucleoside triphosphate; $\mathrm{MgCl}$ : Magnesium dichloride.}

\section{Acknowledgements}

We thank Aymar Ndounga, Prisca Casimiro, Brunelle Matondo for their participation in the field study. We are grateful to the children who participated in the study. FKK, VM, CJV, and PIM received support of CANTAM network. We are grateful to Professor Theonest Mutabingwa for the critical reading and editing of the manuscript.

This work has been supported through the Central Africa Network on Tuberculosis, HIV/AIDs and Malaria (CANTAM), which is a network of excellence supported by EDCTP.

\section{Author details}

${ }^{1}$ Congolese Foundation for Medical Research, Brazzaville, Republic of Congo. ${ }^{2}$ Faculty of Health Sciences, Marien Ngouabi University, Brazzaville, Republic of Congo. ${ }^{3}$ Centre de Recherche sur les Ressources Végétales, Brazzaville, Republic of Congo. ${ }^{4}$ Unité de Recherche sur le Paludisme, Hôpital de Base de Makélékélé, Brazzaville, Republic of Congo. ${ }^{5}$ Institute for Tropical Medicine, University of Tübingen, Tübingen, Germany.

\section{Authors' contributions}

FKK performed DNA extraction, molecular genetic studies, data analysis, and drafted the manuscript. VM and PIM participated in molecular genetic studies, CJV participated in the data analysis. MN designed and supervised the field study. FN supervised the different steps of the work. All authors contributed to the final manuscript.

\section{Competing interests}

The authors declare that they have no competing interests.

Received: 10 January 2012 Accepted: 1 April 2012

Published: 1 April 2012

\section{References}

1. World Health Organization: World malaria report 2010 [http://Whqlibdoc. who.int/publications/2010]

2. World Health Organization: World malaria report 2009 WHO/HTM/GMP/; 2009 .
3. Breman JG, Alilio MS, White LJ: Defining and defeating the intolerable burden of malaria III. Progress and perspectives. Am J Trop Med Hyg 2007, 77:1-2.

4. Curtis CF, Maxwell CA, Magesa SM, Rwegoshora RT, Wilkes TJ: Insecticidetreated bed-nets for malaria mosquito control. J Am Mosq Assoc 2006, 22:501-506.

5. Schwartz L, Brown GV, Genton B, Moorthy VS: A review of malaria vaccine clinical projects based on the WHO rainbow table. Malar J 2012, 11:11.

6. Ntoumi F, Contamin H, Rogier C, Bonnefoy S, Trape JF, MercereauPuijalon O: Age dependent carriage of multiple Plasmodium falciparum merozoite surface antigen-2 alleles in asymptomatic malaria infections. AmJTrop Med Hyg 1995, 52:81-88.

7. Babiker HA, Ranford-Cartwright LC, Walliker D: Genetic structure and dynamics of Plasmodium falciparum infections in the Kilombero region of Tanzania. Trans R Soc Trop Med Hyg 1999, 93:11-14.

8. Smith T, Beck HP, Kitua A, Mwankusye S, Feldrl I, Fraser-Hurt N, Irion A, Alonso P, Teuscher T, Tanner M: Epidemiology of multiple Plasmodium falciparum infections. Age dependence of the multiplicity of Plasmodium falciparum infections and other malariological indices in an area of high endemicity. Trans R Soc Trop Med Hyg 1999, 93:15-20.

9. Vafa M, Troye-Blomberg M, Anchang J, Garcia A, Migot-Nabias F: Multiplicity of Plasmodium falciparum infection in asymptomatic children in Senegal: relation to transmission, age and erythrocyte variants. Malar J 2008, 7:17.

10. Ntoumi F, Mercereau-Puijalon O, Ossari S, Luty A, Reltien J, Georges A Millet P: Plasmodium falciparum: sickle-cell trait is associated with higher prevalence of multiple infections in Gabonese children with asymptomatic infections. Exp Parasitol 1997, 87:39-46.

11. Trape JF, Peelman P, Morault-Peelman B: Criteria for diagnosing clinical malaria among a semi-immune population exposed to intense and perennial transmission. Trans R Soc Trop Med Hyg 1985, 79:435-442.

12. Trape JF, Quinet MC, Nzingoula S, Senga P, Tchichelle F, Carme B, Candito D, Mayanda H, Zoulani A: Malaria and urbanization in the central Africa: the example of Brazzaville. Part V: Pernicious attacks and mortality. Trans R Soc Trop Med Hyg 1987, 81:34-42.

13. Trapsida JM, Mankele $R$, Nzébélé $P$, Okono G: Problématique de l'accès des populations de la ville de Brazzaville aux combinaisons à base d'artémisinine. WHO, The African Health Monitor 2010, 12.

14. Kublin JG, Cortese JF, Njunju EM, Mukadam RA, Wirima JJ, Kazembe PN, Djimdé AA, Kouriba B, Taylor TE, Plove CV: Re-emergence of chloroquinesensitive Plasmodium falciparum malaria after cessation of chloroquine use in Malawi. J Infect Dis 2003, 187:1870-1875.

15. Mita T, Kaneko A, Lum JK, Bwijo B, Takechi M, Zungu IL, Tsukahara T, Tanabe K, Kobayakawa T, Björkman A: Recovery of chloroquine sensitivity and low prevalence of the Plasmodium falciparum chloroquine resistance transporter gene mutation $\mathrm{K} 76 \mathrm{~T}$ following the discontinuance of chloroquine use in Malawi. AmJTrop Med Hyg 2003, 68:413-415.

16. Laufer MK, Thesing PC, Eddington ND, Masonga R, Dzinjalamala FK, Takala SL, Taylor TE, Plowe CV: Return of chloroquine antimalarial efficacy in Malawi. N Engl J Med 2006, 355:1959-1966.

17. Ntoumi F, Ngoundou-Langji J, Lekoulou F, Luty A, Deleron P, Ringwald P: Site-based study on polymorphism of Plasmodium falciparum MSP-1 and MSP-2 genes in isolates from two villages in central Africa. Parasitologia 2000, 42:197-203.

18. Mayengue PI, Ndounga M, Davy MM, Tandou N, Ntoumi F: In vivo chloroquine resistance and prevalence of the pfcrt codon 76 mutation in Plasmodium falciparum isolates from the republic of Congo. Acta Trop 2007, 95:219-225.

19. Djimdé A, Doumbo OK, Cortese JF, Kayentao K, Doumbo S, Diourte $Y$, Dicko A, Su XZ, Nomura T, Fidock DA, Wellems TE, Plowe CV, Coulibaly D: A molecular marker for chloroquine-resistant falciparum malaria. $N$ Engl J Med 2001, 344:257-263.

20. Mayor AG, Gomez-Olive X, Aponte JJ, Casimiro S, Mabunda S, Dgedge M, Barreto A, Alonso PL: Prevalence of the K76T mutation in the putative Plasmodium falciparum chloroquine resistance transporter ( $p f c r t$ ) gene and its relation to chloroquine resistance in Mozambique. J Infect Dis 2001, 183:1413-1416.

21. Wu YD, Ugozzoli L, Pal BK, Wallace BR: Allele-specific enzymatic amplification of $\beta$-globin genomic DNA for diagnosis of sickle cell anemia. Proc Natl Acad Sci USA 1989, 86:2757-2760. 
22. Cortés A, Mellombo M, Benet A, Lorry K, Rare L, Reeder JC: Plasmodium falciparum: distribution of msp2 genotypes among symptomatic and asymptomatic individuals from the Wosera region of Papua new Guinea. Exp Parasitol 2004, 106:22-29.

23. Nkoghe D, Akue JP, Gonzalez JP, Leroy EM: Prevalence of Plasmodium falciparum in asymptomatic rural Gabonese populations. Malar J 2011, 10:33.

24. Mombo LE, Ntoumi F, Bisseye C, Ossari S, Lu CY, Nagel RL, Krishnamoorthy R: Human genetic polymorphisms and asymptomatic Plasmodium falciparum malaria in Gabonese schoolchildren. AmJTrop Med Hyg 2003, 68:186-190.

25. Jafari-Guemouri S, Boudin C, Fievet N, Ndiaye P, Deloron P: Plasmodium falciparum genotype population dynamics in asymptomatic children from Senegal. Microbes Infect 2006, 8:1663-1670.

26. Buchholz U, Kobbe R, Danquah I, Zanger P, Reither K, Abruquah HH, Grobusch MP, Ziniel P, May J, Mockenhaupt FP: Multiplicity of Plasmodium falciparum infection following intermittent preventive treatment in infants. Malar J 2010, 9:244.

27. Färnert A, Lebbad M, Faraja L, Rooth I: Extensive dynamics of Plasmodium falciparum densities, stages and genotyping profiles. Malar J 2008, 7:241.

28. Carlsson AM, Ngasala BE, Dahlström S, Membi C, Veiga IM, Rombo L, Abdullah S, Premji Z, Gil PJ, Björkman A, Martensson A: Plasmodium falciparum population dynamics during the early phase of anti-malarial treatment in Tanzanian children with acute uncomplicated malaria. Malar J 2011, 10:380.

29. Pembe IM, Ndounga M, Malonga FV, Bitemo M, Ntoumi F: Genetic polymorphisms of merozoite surface protein-1 and surface protein-2 in Plasmodium falciparum isolates from Brazzaville. Republic of Congo Malar J 2011, 10:276.

30. Contamin H, Fandeur T, Bonnefoy S, Skouri F, Ntoumi F, MercereauPuijalon O: Typing of field isolates of Plasmodium falciparum. J Clin Microbiol 1996, 33:944-951.

31. Farnert A, Arez AP, Babiker HA, Beck HP, Benito A, Björkman A, Bruce MC, Conway DJ, Day KP, Henning L, Mercereau-Puijalon O, Ranford-

Cartwrigth LC, Rubio JM, Snounou G, Walliker D, Zwetyanga J, Do Rosario VE: Genotyping of Plasmodium falciparum infections by PCR: a comparative multicentre study. Trans R Soc Trop Med Hyg 2001, 95:225-232.

32. Konate L, Zwetyenga J, Rogier C, Bischoff E, Fontenille D, Tall A, Spiegel A, Trape JF, Mercereau-Puijalon O: Variation of Plasmodium falciparum msp1 block2 and msp2 allele prevalence and of infection complexicty in two neighbouring Senegalese villages with different transmission conditions. Trans R Soc Trop Med Hyg 1999, 93:21-28.

33. Hasting IM, Bray PG, Ward SA: A requiem for chloroquine. Science 2002, 298:74-75.

34. Efunshile M, Runsewe-Abiodum T, Ghebremedhin B, König W, König B: Prevalence of molecular marker of chloroquine resistance (pfcrt 76) in Nigeria 5 years after withdrawal of the drug as first-line antimalaria: A cross-sectional study. SA J Child Health 2011, 5:39-41.

doi:10.1186/1475-2875-11-105

Cite this article as: Koukouikila-Koussounda et al: Genetic polymorphism of merozoite surface protein 2 and prevalence of K76T pfcrt mutation in Plasmodium falciparum field isolates from Congolese children with asymptomatic infections. Malaria Journal 2012 11:105.

\section{Submit your next manuscript to BioMed Central and take full advantage of:}

- Convenient online submission

- Thorough peer review

- No space constraints or color figure charges

- Immediate publication on acceptance

- Inclusion in PubMed, CAS, Scopus and Google Scholar

- Research which is freely available for redistribution

Submit your manuscript at www.biomedcentral.com/submit
Biomed Central 